\title{
DEFININDO ESPAÇOS DE EDUCAÇÃO CRIATIVA NO ENSINO SUPERIOR DE ADMINISTRAÇÃO ATRAVÉS DE MECANISMOS DE COCRIAÇÃO DE VALOR
}

\author{
DEFINING SPACES OF CREATIVE EDUCATIONAL AT MANAGEMENT HIGHER
}

\author{
EDUCATION THROUGH A VALUE CREATION MECHANISM
}

Recebido em: 02/12/2018 • Aprovado em: 12/04/2019

Avaliado pelo sistema double blind review Editor Científico: Edson Sadao Iizuka DOI 10.13058/raep.2019.v20n2.1340

\section{ADRIANA FUMI CHIM-MIKI adriana.chimmiki@gmail.com DANIELI BARBOSA CAMPOS LUCIA SILVA ALBUQUERQUE DE MELO}

Universidade Federal de Campina Grande

\begin{abstract}
RESUMO
A pesquisa objetivou identificar os elementos e forma dos espaços de educação criativa pela ótica dos principais atores envolvidos no âmbito da educação universitária em administração. O estudo se fundamenta em três perspectivas teóricas: cocriação de valor, espaços criativos de educação e inovação educativa. A metodologia utilizada é de natureza exploratória e qualitativa, que realiza um processo de cocriação de valor, utilizando a técnica de Focus Group com uma amostragem intencional de professores, estudantes, servidores e direção em uma universidade brasileira. Os resultados indicam alinhamento com as abordagens de inovação educativa e espaços criativos, no que tange a inovação institucional, especificamente estrutural e didática. $\mathrm{O}$ modelo ideal de espaço criativo de educação cocriado pelo grupo mantém semelhança com os espaços de coworking e de estruturas organizacionais de empresas não tradicionais. Verificou-se consenso entre professores e alunos de que as atuais salas de aula utilizadas, na grande maioria das universidades, estão ultrapassadas e é desestimulante para a criatividade, tanto para educadores como para estudantes, devendo ser repensadas, sob pena de serem um dos pontos geradores da evasão escolar. O espaço criativo de educação foi associado a interação, tecnologias, funcionalidades, gamificação e ócio criativo.
\end{abstract}

Palavras-Chave: Cocriação de valor. Espaço criativo de educação. Inovação educativa. Universidade. Focus Group.

\begin{abstract}
The research goal was to identify the elements and form of creative educational spaces from the perspective of the main actors involved in the context of higher education in management. The study is based on three theoretical aspects: value co-creation, creative spaces of education and, educative innovation. The methodology was exploratory and qualitative, that performs a process of value co-creation using the Focus Group technique with an intentional sampling of teachers, students, employee, and head department of a Brazilian university. The results indicate alignment with the approaches of educative innovation and creative spaces regarding institutional innovation structural and didactic. The ideal model of creative education space co-created by the group maintains similarity with the coworking spaces and organizational structures of non-traditional firms. A consensus among teachers and students considered the current classrooms, used in most universities, as outdated and, discouraging of creativity for both educators and students and should be rethought on pain of being one of the points generated from school dropout. The creative space of education was associated with the interaction, technologies, functionalities, gamification and creative leisure.

Keywords: Value co-creation. Educational creative space. Educational innovation. Higher education. Focus Group.
\end{abstract}




\section{INTRODUÇÃO}

Cocriação é o processo pelo qual o valor mútuo é expandido em conjunto (RAMASWAMY, 2011). Nos dias atuais, vem-se notando a necessidade de mudança no ambiente educacional e, principalmente, na estrutura física das salas de aula para atender a um novo perfil de educandos e de educadores, assim como a um mercado baseado em inovação.

Nesse sentido, a cocriação de valor se mostra um procedimento de grande suporte para que essa mudança aconteça, como mecanismo que pode dar resposta a adaptações na estrutura mais básica de uma instituição de ensino: sua sala de aula. O processo de cocriar valor proporciona mecanismos mais efetivos para a extração do conhecimento e experiência acumulada dos usuários, dos produtos e serviços das empresas (PRAHALAD; RAMASWAMY, 2004).

As salas de aula clássicas tendem a dar espaço a salas voltadas para a educação criativa, que vem a ser áreas lúdicas e interativas, onde o ser humano possa desenvolver seu potencial de uma força mais criativa, contando com uma estrutura que facilite esse desenvolvimento (BERNAL VÁZQUEZ, 2006; FINI, 2018). A implementação de espaços criativos de educação e a interação gerada entre educandos e educadores pode atingir um duplo viés: proporcionar a inovação educativa e o fomento de soluções inovadoras para a sociedade (BECKER et al. 2017).

Aspectos relacionados a espaços criativos de educação têm sido apontados na literatura, por exemplo: flexibilidade, interação (ROMERO, 2013); equilíbrio entre liberdade e estrutura (NICKERSON,1999; ALONSO MONREAL, 2000); estruturas socializantes (AMABILE, 1996); estruturas ricas de estímulos (TORRE, 2006); estruturas físicas mais dinâmicas, interativas e colaborativas para o aprendizado (SILVA; SILVA; COELHO, 2016; SILVA et al., 2018); bem como comporta atividades multidisciplinares, de ensino-equipe, sensações estimuladoras e participativas em sala de aula, permite trocar experiências, diálogo, possibilita conforto, sensação de segurança e tranquilidade (SILVA; SANTOS, 2015). 
Também é preciso destacar que algumas empresas, como a Google, têm adotado esses espaços criativos como parte de sua estrutura organizacional, assim como tem apoiado esse modelo no contexto do ensino secundário, fomentando as chamadas sala Google de Educação, as quais são associadas à inovação e à criatividade (IFTAKHAR, 2016; BOTTENTUIT JUNIOR; LISBÔA; COUTINHO, 2011). No entanto, as universidades, na sua maioria, ainda mantêm seu tradicional modelo de ensino e estruturas físicas, encontrando-se poucos casos-modelos para servir de base bibliográfica prática aos que quiserem se aventurar nesse novo padrão, conforme pode ser verificado nos estudos relacionados ao tema na fundamental teórica (ARCHER; GARRISON; ANDERSON, 2013; BRUBACHER, 2017).

Dessa forma, este trabalho se justifica tanto por uma necessidade de mercado/sociedade, quanto pela escassez de pesquisas nesta temática no âmbito universitário. Essa lacuna literária nos conduz a seguinte questão: como deve ser o espaço físicos de educação criativa, na universidade, no ensino da administração? Para responder a esta questão, realizou-se uma pesquisa qualitativa e exploratória com objetivo de identificar os elementos e forma dos espaços físicos de educação criativa pela ótica dos principais atores (coletivos) envolvidos no âmbito da educação universitária presencial em administração. Utilizou-se a técnica de Focus Group na Universidade Federal de Campina Grande, localizada na Paraíba, para operacionalizar um processo de cocriação de valor, conforme o passo a passo indicado por Prahalad e Rasmawamy (2004), permitindo identificar os elementos que venham a tornar a sala de aula clássica em um espaço de educação criativa para o curso de administração dentro da universidade.

Assim, o presente trabalho, além de elencar itens que são associados ao espaço criativo no meio universitário, voltado para o curso de administração, testa a técnica de Focus Group como método para o estabelecimento de plataformas de cocriação de valor, de acordo com o passo a passo indicado por Prahalad e Ramaswamy (2004).

A partir dessa introdução, o trabalho se organiza com uma seção de fundamentação que aborda três eixos: a teoria de cocriação de valor e suas 
novas fronteiras, os espaços de educação criativa e suas características e a inovação educativa. Por sua vez, a terceira seção é dedicada a explicar as escolhas metodológicas, processos e amostragem. Por fim, há a seção de apresentação de resultados, análises e considerações finais, que resumem os principais pontos gerados a partir do Focus Group, portanto, o produto final cocriado pelos coletivos, ou seja, principais grupos de atores. 


\section{FUNDAMENTAÇÃO TEÓRICA}

\section{Cocriação de Valor: Origens, Conceitos e Estratégias}

Cocriação é um termo de marketing que começou a ser utilizado a partir do artigo Co-opting Customer Competence publicado na Harvard Business Review em 2000 de autoria de C.K. Prahalad e Venkat Ramaswamy. Nesse artigo, os autores destacam o aproveitamento das experiências e competências do consumidor na geração de produtos e serviços e salientam a diferença entre cocriação e customização (personalização), pois o primeiro caso ocorre em conjunto com outros clientes e busca uma generalização do novo produto ou serviço, enquanto o segundo caso, são experiências individuais para produtos personalizados (PRAHALAD; RAMASWAMY, 2000). A difusão, porém, dessa perspectiva como ferramenta nas organizações se intensificou a partir do lançamento do best-seller "The future of competition: Co-creating unique value with customers" de C. K. Prahalad e Venkat Ramaswamy, em 2004. De fato, em meio a tantas inovações, para as empresas que buscam novas ideias para seus produtos ou serviços. Assim, os processos de cocriação de valor passaram a ser fundamentais para a competitividade empresarial. Na era da modernização e consumo tem se tornado mais comum o uso dessa ferramenta que vem adequando o mercado às exigências do consumidor final, provocando a interação entre os grupos de interesse das empresas (stakeholders) que buscam agregar valor e inovar nos produtos ou serviços oferecidos, desde uma perspectiva de criação de valor mútuo (RAMASWAMY; OZCAN, 2018; PRAHALAD; RAMASWAMY, 2004).

Apesar da cocriação de valor, enquanto processo formalizado em plataformas de partes interessadas, ter ganhado notoriedade, principalmente a partir das publicações de Prahalad, Ramaswany e Ozcan, a cocriação de valor provém de três perspectivas teóricas anteriores (CHIM-MIKI; GÂNDARA; BATISTA-CANINO, 2017). A primeira é a lógica serviço-dominante (Lógica S-D), de Vargo e Lusch (2004, 2011), que define o cliente como um recurso operante com diferentes habilidades e conhecimentos e que afeta a forma como o valor é criado quando o serviço é consumido. 
Como resultado, a relação de consumo sempre gera cocriação de valor (PRAHALAD; RAMASWAMY, 2000). A segunda se refere às correntes teóricas que são baseadas na perspectiva da lógica de serviço (SD) que considera que o cliente cria valor quando combina recursos fornecidos pela empresa a outros recursos em sua prática diária (GRÖNROOS, 2008), mas que o valor se cria somente quando as interações são estabelecidas por meio de plataformas formais. A terceira perspectiva, que embasou as origens da cocriação, provém das abordagens da ciência de serviços. Esse ponto de vista considera que a cocriação de valor ocorre por meio da interação entre os recursos disponíveis em vários sistemas de serviços sendo, portanto, focada na criação de valor em nível macro (CHIM-MIKI; GÂNDARA; BATISTA-CANINO, 2017; SAARIJÄRVI; KANNAN; KUUSELA, 2013).

Gonzalez e Jemison (1989) já definiam o conceito de cocriação de valor de forma muito simples, como um processo pelo qual os recursos de duas empresas se combinam para se alcançar algo que uma das partes não alcançaria sozinha. A diferença principal nas novas vertentes derivadas da ótica de Vargo e Lusch $(2004,2011)$ e Grönroos (2008) e que resulta na perspectiva de cocriação de valor, segundo Prahalad e Ramaswamy (2000, 2004), está na participação do cliente e outros públicos e não apenas a interação entre duas empresas. Proporcionou-se uma reinvenção na forma como o valor é criado, a qual também se apoia na ideia de coprodução de valor em oposição à ideia tradicional de criação de valor industrial. $\mathrm{Na}$ criação de valor industrial, os clientes eram vistos como destruidores do valor que os produtores lhes criaram (RAMIREZ, 1999). Enquanto, na atualidade, o cliente é criador de valor tanto quanto a empresa.

Um dos pontos que estimulou os pesquisadores Prahalad e Ramaswamy (2004) a re-pensar a teoria da cocriação de valor foi o paradoxo no mundo corporativo do século atual, em que cada vez mais escolhas são disponibilizadas aos consumidores, sem que os ofertantes lhes consigam assegurar a obtenção de satisfação. Esse paradoxo conduziu os autores a uma ideia fundamental: a criação de valor deixou de ser um processo unilateral para tornar-se multilateral sendo um processo em que o cliente tem papel determinante. Assim, o que direciona a cocriação é envolver as pessoas 
para criar experiências valiosas em conjunto, reforçando simultaneamente a economia de rede, portanto, cocriação é o processo pelo qual o valor mútuo é expandido em conjunto (RAMASWAMY, 2011).

Dessa forma, nota-se que a cocriação de valor depende da interação e da integração entre as partes envolvidas no processo para um bom desempenho nas organizações, sendo parte da estratégia competitiva da empresa em busca de posicionamento. Trata-se identificar o "valor percebido pelo cliente", conceituado por Hamel e Prahalad (2002) como os benefícios que o cliente vê ao usufruir do produto/serviço adquirido, a fim de melhorar seu desempenho e inovar. Nesse contexto, algumas empresas já consolidaram o uso do processo de cocriação de valor, por exemplo, a Lego, a Starbucks, a Nike, a Pepsi, o Boticário (PRAHALAD; RAMASWAMY, 2004).

A perspectiva de cocriação iniciou a partir da visão de interação entre a empresa e seu público consumidor, porém os recentes trabalhos, assim como as atuais aplicações empresariais, mostram uma maior abrangência de participantes na criação de valor, o que tem sido destacada por Ramaswany e Gouillart (2010) como a nova fronteira de cocriação, criada a partir de diversos stakeholders da empresa. Nesse caso, extrapolou-se a participação no processo de cocriar valor do cliente para todos os públicos interessados da empresa gerando plataformas e ferramentas interativas e abertas (BLACK; VELOUTSOU, 2017).

As empresas interessadas em ferramentas de cocriação de valor buscam estabelecer formas de manterem o contato com seus clientes para um maior fluxo de feedback, de modo que elas podem se estruturar mais adequadamente para que seu produto ou serviço seja melhor posicionado no mercado (SELTZER; MAHMOUDI, 2013; BLACK; VELOUTSOU, 2017). A internet é um dos meios que possibilitou a comunicação, de consumidores com consumidores, permitindo o compartilhamento de ideias, desconsiderando as barreiras sociais e geográficas, consentindo ao consumidor expressar suas opiniões em uma proporção sem antecedentes e potencializando a aplicação dos processos de cocriação de valor (PRAHALAD; RAMASWAMY, 2004). 
Apesar do destacado fluxo de informações online, na fronteira da cocriação de valor enquanto estratégia empresarial, existe uma diferença entre as informações extraídas de comentários de clientes na internet em websites, fóruns e outros mecanismos e um formalizado processo de cocriação de valor. Prahalad e Ramaswamy (2004) consideram que a cocriação realmente ocorre quando se desenvolvem instrumentos para formalizar o processo e, assim, os autores recomendam alguns passos que devem ser seguidos para cocriação de valor na organização, que são:

1. Identificar os stakeholders que são impactados pelo processo (funcionários, clientes, fornecedores, distribuidores, comunidade);

2. Compreender e delinear interações atuais entre grupos de interesse;

3. Organizar workshops em que grupos de interesse compartilhem experiências e imaginem oportunidades de melhoria;

4. Construir plataformas online formalizadas com o propósito de estabelecer um espaço para novas interações e continuar um diálogo entre os grupos de interesse para gerar novas ideias.

Numa linha similar de pensamento, Payne, Storbacka e Frow (2008) destacaram formas para as organizações criarem valor em processos que remetem a Vargo e Lusch (2004). Esses autores enfatizam um conjunto de processos e de recursos com os quais a empresa busca criar propostas de valor e cujas modelagens possuem três componentes principais: o cliente, o ofertante e o processo de encontro dessas visões, de forma a aproveitar a experiência de consumo como fonte de informações, sendo balizadas pela emoção, cognição e comportamento que, por meio de um processo adequadamente conduzido, produzirá aprendizado organizacional (PAYNE; STORBACKA; FROW, 2008).

\section{Espaços Criativos e a Inovação Educativa na Universidade}

O espaço criativo deve ser uma área que ajude o ser humano a desenvolver seu potencial, logo deve possuir estrutura que facilite o desenvolvimen- 
to pessoal e interpessoal (BERNAL VÁZQUEZ, 2006). Existem diferentes abordagens na literatura dessa temática e disso derivam características que o espaço criativo deve ter para o desenvolvimento da criatividade. Por exemplo, Logan e Logan (1980) sugerem foco na flexibilidade, imaginação, auto-direção e integração, mas salientam que este formato tem recompensas e riscos (Figura 1).

Figura 1 Características do espaço criativo de educação

\begin{tabular}{|c|c|}
\hline \multirow{9}{*}{ 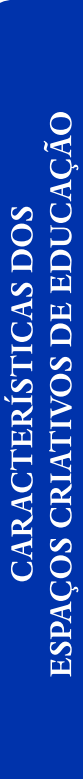 } & Ser flexível, para uma boa adaptação dos alunos \\
\hline & $\begin{array}{l}\text { Proporcionar o uso de métodos de ensino indiretos para assim motivar } \\
\text { a consulta e descoberta }\end{array}$ \\
\hline & Ser imaginativo, pois é fundamental para um ensino criativo \\
\hline & $\begin{array}{l}\text { Ser uma combinação Inteligente entre métodos, ideias, mídia e } \\
\text { matérias de apoio }\end{array}$ \\
\hline & Incentivar a interação entre os alunos e professores \\
\hline & $\begin{array}{l}\text { Integrar o currículo para que os alunos vejam a relação existente } \\
\text { com a educação criativa }\end{array}$ \\
\hline & $\begin{array}{l}\text { Possibilitar a auto direção do aluno, para que a curiosidade, pesquisa, } \\
\text { experimentação e investigação sejam desenvolvidas }\end{array}$ \\
\hline & Proporcionar a auto avaliação para o melhor desenvolvimento criativo \\
\hline & Envolve riscos, mas também fornece recompensas \\
\hline
\end{tabular}

Fonte: Elaborado pelos autores a partir de Logan e Logan (1980).

O conhecimento é construído por meio da criatividade de cada pessoa, e melhorar o potencial criativo ao longo do tempo deve ser um objetivo no sistema educativo. Nesse sentido, abordagens teórico-empíricas têm sido propostas para melhorar a criatividade dentro do ambiente educacional, utilizando metodologias mais ativas (FINI, 2018). A proposta de Alonso Monreal (2000) sugere que, para a melhoria da criatividade, deve-se considerar que as atitudes não são ensinadas com regras, mas com o exemplo, sendo, então, necessário: 
1. Afirmação de intenções e interações - refere-se à necessidade de trabalho contínuo para tornar a criatividade possível;

2. Construção de habilidades básicas - três níveis de desenvolvimento são necessários: aquisição de habilidades básicas, como linguagem; a aprendizagem de sistemas estruturados de resolução de problemas; e a execução de projetos autônomos independentes;

3. Aquisição de conhecimentos específicos dos domínios;

4. Estimulação da curiosidade;

5. Construção de motivação;

6. Autoconfiança e disposição para o risco - expressão de suas próprias ideais e apoio ao sucesso, interpretação de fracassos e não como fraqueza;

7. Concentrar-se em especialização e desempenho próprio;

8. Incentivar crenças que apoiem a criatividade, por exemplo: a conviç̧ão de que a criatividade é determinada em grande parte pela motivação e pelo esforço;

9. Dar oportunidades de escolha e de descoberta;

10. Desenvolver habilidades de auto direção;

11. Ensinar técnicas e estratégias para facilitar o desempenho criativo;

12. Fornecer equilíbrio entre liberdade e estrutura.

Por outro lado, Amabile (1996) opera no âmbito da chamada abordagem ambientalista à criatividade, para o qual este autor aponta dois fatores que estão envolvidos para a melhoria da criatividade na educação: os fatores gerais e os fatores sociais (Quadro 1). Nessa perspectiva, o ambiente para a educação criativa vai além do espaço físico, alcançando métodos e comportamentos. 
Quadro 1 Fatores para melhoria da criatividade na educação

\section{FATORES GERAIS}

a. Desenvolvimento de habilidades de aprendizagem.

b. Métodos de ensino;

c. Comportamentos do professor;

d. O relacionamento e influência dos colegas;

e. Perigos da educação.

\section{FATORES SOCIAIS}

a. Socialização (famílias menos afetadas pela convenção social favorecem mais a criatividade). É importante que as crianças sejam confrontadas com modelos criativos desde tenra idade;

b. Atitudes para o trabalho;

c. Controle e criatividade;

d. Os prêmios e recompensas;

e. Diferenças individuais.

Fonte: Elaborado com base em Amabile (1996).

Em síntese, o espaço criativo deve ser composto pelos seguintes atores: o educador, o aluno, o clima educacional e as técnicas ou programas criativos. Este ambiente educacional deve proporcionar: (1) riqueza de estímulos eficaz para o desenvolvimento de habilidades cognitivas e criatividade; (2) interação e transformação; (3) cultivo da criatividade usando técnicas e ferramentas de suporte; (4) polinização de ideais por meio de adequada comunicação (TORRE, 2006).

A criatividade no cenário educacional se torna a base decisiva nos processos de construção do conhecimento, tornando-o cada vez mais amplo. Nesse sentido, a Universidade precisa repensar seus espaços de sala de aula e não somente suas técnicas pedagógicas, pois seus espaços educacionais devem proporcionar estímulos, interação, sociabilização, ser imaginativos, ter uma combinação inteligente entre métodos, ideias, mídia e matérias de apoio (LOGAN; LOGAN, 1980; ALONSO MONREAL, 2000; FINI, 2018).

Ainda sobre a educação criativa, Loi e Dillon (2006) falam que a criatividade depende de vários fatores e destacam o papel do professor como parte fundamental para as intervenções na criação de aprendizagem criativa, mostrando que espaços criativos jamais surgem ao acaso. Os autores afirmam, assim, que a criatividade é um fenômeno situacional que depende 
das interações entre os sujeitos e os contextos, levando em consideração o nível de envolvimento, motivação, colaboração e interação entre os envolvidos no processo de inovação na educação criativa (LOGAN; LOGAN,1980).

A forma de ensino tradicional é apontada como geradora de um desenvolvimento limitado, fazendo com que a criatividade esteja relacionada apenas a formular e resolver problemas e não inovar (BECKER et al., 2017). Por outro lado, Bacich e Moran (2017) afirmaram que a inovação na educação, fundamentada na criatividade, é possível por meio de mudanças na forma de ensino tanto nas escolas como nas universidades e que os espaços criativos têm o poder de despertar o lado criativo de todos os envolvidos no processo de aprendizagem, incluindo estudantes e professores (MCKENNEY; REEVES, 2018; CATHCART; ESLAND, 2017). Portanto, a educação inovadora baseada em espaços criativos deve proporcionar que as tarefas de aprendizagem sejam orientadas para a busca de problemas e soluções a partir de diferentes perspectivas e procedimentos, gerando soluções inovadoras. Esses espaços oferecerão mais possibilidades de aprender e criar propostas como totalidades complexas, nas quais os alunos devem colocar em jogo vários conhecimentos, procedimentos e estratégias (ELISONDO; DONOLO; RINAUDO, 2009; FINI, 2018).

\section{Espaços Criativos de Educação e a Cocriação de Valor}

No âmbito educacional o êxito de uma inovação depende da capacidade para articular uma reciprocidade entre o sistema social e o educativo (BECKER et al., 2017). Um modelo de inovação educativa deve proporcionar um marco para a realização de autênticas inovações, uma busca de soluções, possibilitando a formação, desenvolvimento e interiorização da cultura de inovação (MCKENNEY; REEVES, 2018). Nesse contexto, a criatividade, como um impulsionador da inovação, deve ser propiciada dentro das instituições de ensino, bem como a criação de espaços que possibilitem a educação inovadora. Porém, não se trata somente de introduzir algo novo no cenário educativo, mas revisar as práticas pedagógicas rígidas e os ambientes de trabalho e ensino, gerando inovação educativa 
(LIBEDINSKY, 2001, 2011). Essa autora classifica a inovação educativa em (i) Institucional (administrativa, físico-estrutural, organizacional etc.), (ii) curricular (estrutura curricular, práticas de avaliação curricular etc.) (iii) didática (planejamento e intervenção didática, avaliação do aprendizado, desenho de instrumento e estratégias de ensino etc).

Inovação é a introdução de um novo ou significantemente melhorado produto (bem ou serviço), de um processo, de um novo método de comercialização ou de um novo método organizacional, nas práticas internas da empresa, da organização do lugar de trabalho ou das relações exteriores (MEDINA-MUÑOZ; MEDINA-MUÑOZ; ZÚÑIGA-COLLAZOS, 2013). Desta forma, pode-se considerar que os espaços criativos de educação tendem a atender vários aspectos ao proporcionar inovação institucional e didática. Assim, pode conduzir a um repensar não somente os espaços e estruturas dos programas universitários, mas também pode conduzir a inovações curriculares.

Nesse contexto, a perspectiva teórica da nova fronteira da cocriação de valor (PRAHALAD; RASMAWANY, 2004; RAMASWANY; GOUILLART, 2010), aplicada ao ambiente educacional, conduz à inovação educativa, sendo os stakeholders (professores, alunos, servidores e o mercado de trabalho) os atores deste processo, os coletivos envolvidos. Desse modo, Liburd e Hjalager (2010) destacam que a educação precisa sair desse modelo tradicional e alcançar um modelo de inovação, atendendo à necessidade do mercado, indo além das paredes da universidade.

Complementando essas visões, Ramaswamy e Ozcan (2018) oferecem uma recente perspectiva e unificadora ao ancorar sua teorização na criação por meio de interações. Segundo esses autores, a cocriação é um agenciamento de criação interacional por meio de ambientes de sistemas, fornecidos por plataformas interativas que envolve o compromisso de agenciamento e as organizações estruturantes. As plataformas interativas são compostas de relações heterogêneas de artefatos, processos, interfaces e pessoas, com a ajuda das tecnologias digitalizadas, mas podendo também ser conduzidas em processos presenciais (RAMASWAMY; OZCAN, 2018). 


\section{Estudos Relacionados ao Tema}

Para identificar quais perspectivas teóricas e práticas dos espaços de educação criativa no ensino superior de Administração vêm sendo consideradas e propostas pela literatura brasileira foi elaborado um protocolo de pesquisa baseado nos dois critérios. Primeiro, acesso aos anais dos congressos científicos brasileiros da área de Administração considerando a representatividade destes eventos no cenário nacional no âmbito do Ensino e Pesquisa em Administração. Dessa forma, delimitou-se como base de pesquisa as publicações da Associação Nacional de Pós-Graduação em Administração (ANPAD), especificamente, os eventos: Encontro da ANPAD (EnANPAD - edições de 2014-2018), Encontro de Ensino e Pesquisa em Administração e Contabilidade (EnEPQ - edições de 2011, 2013, 2015 e 2018).

Relacionado aos periódicos científicos, foram verificados as edições do periódico Administração: Ensino e Pesquisa (RAEP), no período de 2009 a 2018 e uma busca na base de dados Scientific Periodicals Electronic Library - SPELL e no Google acadêmico. A busca considerou os artigos que tiveram os seguintes termos: Cocriação de valor; Espaço criativo de educação; Inovação educativa e Ambiente de Aprendizagem.

No tocante aos artigos nos eventos científicos foram encontrados os trabalhos de Matias et al (2015); Silva e Santos (2015); Padula (2016); Silva, Silva e Coelho (2016); Fiorin e Silva (2018).

Matias et al (2015) buscaram identificar os benefícios da cocriação de valor em um curso de Administração da Faculdade Capivari. O estudo resultou na identificação de maior produtividade no processo de ensino e de aprendizagem; trouxe benefícios na medida em que aumentou o sentimento de pertencimento dos alunos; e possibilitou maior interação entre docente e estudante, proporcionando maior satisfação dos discentes em seu curso de graduação.

Silva e Santos (2015) descreveram as contribuições do ambiente de aprendizagem projetado no Observatório de Pesquisa e Prática em Administração (OPPA) da Universidade Federal da Paraíba nas experiências vivenciadas pelos alunos de graduação em Administração. Os achados de- 
monstraram que o ambiente projetado no OPPA colaborou no processo de aprendizagem, propiciando sensações estimuladoras e participativas em sala de aula, ao permitir que os alunos possam trocar experiências, dialogar com os demais colegas, possibilitar conforto, sensação de segurança e tranquilidade nos momentos vivenciados, contribuindo na concentração, criatividade e nos processos de reflexão. $\mathrm{O}$ ambiente de aprendizagem projetado comporta atividades multidisciplinares de ensino-equipe, interativas e desvinculadas de limitações que possam restringir o processo de formação.

A pesquisa de Padula (2016) verificou os ganhos na utilização da tecnologia (ferramentas digitais) para aumentar o interesse e conhecimento dos alunos do curso de Administração. Os resultados se mostraram positivos, pois as atividades levaram os alunos a uma reflexão e aprimoramento visando ao futuro em suas carreiras.

Silva, Silva e Coelho (2016) analisaram as implicações do ambiente de aprendizagem na formação de Mestres Profissionais (MP) em Administração. Os resultados destacam para amplitude do inter-relacionamento entre as dimensões Física, Psicológica, Social e Tecnológica que integram o Ambiente de Aprendizagem. Os achados apontam a visão de que um dos desafios na formação de mestres é criar ambientes de aprendizagem nos quais o conhecimento seja propagado de forma construtiva e cujas estruturas fisicas sejam mais dinâmicas, interativas e colaborativas para o aprendizado.

O estudo de Fiorin e Silva (2018) objetivou compreender, sob a ótica da abordagem estética, como as condições ambientais da sala de aula suscitam sentimentos diversos em discentes e docentes, que possam interferir no processo de ensino e de aprendizagem. Os resultados demonstraram que há um descontentamento e desconforto que interferem efetivamente no processo de ensino e de aprendizagem: a sala é áspera, rugosa, tem cheiro de mofo, o som dela é ruim, é fria como azulejo. A sala idealizada é uma sala mais flexível, mais horizontalizada, sobretudo confortável, com um espaço diferenciado, capaz de dar mobilidade para os diferentes arranjos.

Na pesquisa no periódico RAEP, foram encontrados os estudos de Brambilla e Damacena (2012) e Grillo et al (2014). Brambilla e Damace- 
na (2012) realizaram um estudo de cocriação de valor no ensino superior privado, a partir de uma análise etnometodológica com alunos de administração. Esse estudo possibilitou insights das práticas de cocriação no ensino superior e na formação de sentido pelos discentes.

O trabalho de Grillo et al (2014) pesquisou a cocriação de valor com alunos de duas universidades do Rio Grande do Sul, buscando uma análise da influência social e do engajamento na disciplina como antecedentes de feedback do estudante. Os resultados analisados demonstram relações positivas e com significância entre os constructos, evidenciando que, no contexto de sala de aula, processos sociais afetam o relacionamento do discente com a disciplina e que esse relacionamento propicia o comportamento de colaboração para a melhoria das aulas.

Portanto, percebe-se uma lacuna no que diz respeito a um estudo sobre os elementos e forma dos espaços de educação criativa pela ótica dos principais atores envolvidos no âmbito da educação universitária. Então, essa pesquisa se propõe a preencher essa lacuna ao discutir os espaços de educação criativa no ensino de administração por meio de mecanismos de cocriação de valor. 


\section{ASPECTOS METODOLÓGICOS}

A pesquisa realizada é de caráter exploratório, com a abordagem qualitativa que, de acordo com Batista-Canino, Bolívar-Cruz e MedinaBrito (2015), permite ao pesquisador reunir informações a partir de um enfoque válido e valioso que aprofunda realidades complexas. A técnica de Focus group foi escolhida para auxiliar a instauração de um processo de cocriação de valor segundo o passo a passo de Prahalad e Ramaswamy (2004), anteriormente apresentado. Entretanto, nesta pesquisa o processo foi formalizado através de um agenciamento de cocriação de valor interacional em processos presenciais, como indicado por Rasmawamy e Ozcan (2018). No processo de cocriar valor o primeiro passo é identificar os stakeholders, ou seja, os coletivos envolvidos, assim, adaptando a esta pesquisa, corresponde aos representantes da amostra que participarão da seção de Focus Group.

O objetivo da pesquisa é identificar os elementos e forma dos espaços criativos de educação (estruturas) a partir da ótica de seus principais coletivos, assim, para um processo de cocriação de valor relacionado a estes espaços no ensino presencial da Administração, no âmbito universitário, foi selecionado por conveniência o Curso de Administração na Universidade Federal de Campina Grande - UFCG. No presente estudo, os principais grupos de coletivos foram definidos como alunos, professores e funcionários da Unidade Acadêmica de Administração da UFCG.

A Universidade Federal de Campina Grande (UFCG), localizada na Paraíba, tem aproximadamente 15.000 alunos e 1.500 professores distribuídos em 7 Campis, sendo o principal localizado na cidade de Campina Grande, onde está situada a Unidade de Administração e Contabilidade que aloca o curso presencial de Administração e o Programa de Pós-Graduação em Administração. O bacharelado em Administração funciona há 40 anos, tendo, atualmente, 23 professores no seu quadro docente e 390 alunos distribuídos em cursos diurno e noturno. É o único curso de graduação em Administração com nota 5 do ENADE (Exame Nacional de Desempenho de Estudantes) na Paraíba. Desde 2018, conta com o 
Mestrado em Administração ( $1^{a}$ turma), cujo corpo docente permanente é formado por 15 doutores.

$\mathrm{Na}$ escolha dos participantes da pesquisa, para melhorar a confiabilidade dos resultados, foram definidos parâmetros para a amostragem intencional, a saber: (1) os alunos deveriam ser de diferentes níveis no curso; (2) deveria ser incluído pelo menos um aluno de nível de pós-graduação em administração; (3) os professores deveriam ser de diferentes áreas/disciplinas e (4) um dos professores deveria ser representante da coordenação acadêmica.

O segundo passo indicado por Prahalad e Rasmawamy (2004) é compreender e delinear as interações entre o grupo de interesse. No caso do espaço criativo de educação, a interação entre os coletivos ocorre pelo próprio processo educativo (professor-aluno e vice-versa) e pelo atendimento das necessidades dos alunos e professores, que muitas vezes são feitas pelos funcionários administrativos da instituição. Outra interação é entre os alunos de graduação e de pós-graduação que ocorre tanto por estágios docentes, como por participações em grupos de pesquisa.

O próximo passo indicado por Prahalad e Ramaswamy (2004) é a organização de workshops que, nesse caso, foi realizado pela técnica de pesquisa Focus group, pois promove uma maior interação entre os coletivos por meio de reunião, na qual são levantadas as questões relacionadas à pesquisa, seguindo um processo de cocriação de valor por agenciamento e processo presencial (RASMAWAMY; OZCAN, 2018).

O Focus group, de origem anglo-saxã, popularizou-se como técnica nos âmbitos da pesquisa social e de mercado e, posteriormente, estabeleceu-se como boa parte da fundamentação metodológica dos partidários dos métodos qualitativos na Espanha (GODOI, 2015). De forma simples, pode-se afirmar que o Focus Group é um grupo artificial, convocado em função dos objetivos da pesquisa e controlado pelo pesquisador, devendo haver o cuidado de não confundir com Grupo de Discussão (GD). Gutierrez (2011) salienta que há semelhanças entre as técnicas, já que ambas servem para registrar discurso grupal, mas a diferenciação está no consenso. O Focus Group busca levantar ideias, opiniões e definições, desde diferentes cole- 
tivos de uma comunidade, mas não necessariamente promove o consenso sobre uma ideia final (GUTIERREZ, 2011; GODOI, 2015).

Merton (1990) indica que a realização de um Focus Group deve partir do pressuposto de um consenso discursivo prévio e aceitado, no qual a discussão, tanto organizada como dirigida, deve ser a partir de experiências particulares, focalizado em aspectos concretos dos objetivos da pesquisa, trabalhando com sugestões e propostas que ativam e acrescentam discurso. Recomenda-se a presença de um moderador que seja um motor do grupo, lançando perguntas ao grupo e, algumas vezes, oferecendo-lhe respostas, desde a posição de suposta liderança, para que os participantes não deixem de abordar os temas que lhes propõem.

Quantoao tamanho do Focus Group, érecomendadoaproximadamente 10 participantes (MENTON, 1990; GODOI, 2015). Estes autores indicam que a dinâmica da reunião pode lançar mão de um roteiro que auxilie a condução da coleta do material discursivo. Basicamente, as seguintes fases são recomendadas para a aplicação deste método:

$\checkmark$ Fase 1: (a) preparar com antecedência as questões chaves; (b) estabelecer como será registrada as opiniões; e (c) Listar os materiais necessários.

$\checkmark$ Fase 2: (a) definir quem vai participar, buscando o equilíbrio do grupo em termos de representatividade da comunidade que faz parte do objeto de análise; e (b) formalizar os convites e confirmações de presença.

$\checkmark$ Fase 3: (a) dar início a discussão de acordo com roteiro previamente preparado e comunicado aos participantes; (b) dividir os participantes em grupos de dois ou três para falar sobre o assunto e pedir para colocarem as ideias do grupo, no intuito de compartilhá-las com todos; (c) coletar as informações registrando-as; e (d) finalizar as discussões agradecendo aos participantes, resumindo os principais pontos abordados e explicando ao grupo como as informações serão usadas a seguir. 
Assim, seguindo as indicações bibliográficas do uso desta técnica, foi realizada uma seção de Focus Group na Unidade Acadêmica de Administração e Contabilidade (UAAC), da Universidade Federal de Campina Grande, no dia 05 de julho de 2018 , às 08 h30min. na sala 09 do $\mathrm{CH}$, térreo (LABES$\mathrm{PA})$, tendo a presença de 10 participantes, 2 secretárias e o pesquisador principal. As respostas foram gravadas em áudio e, posteriormente, transcritas. Além disso, durante toda a reunião do Focus group, duas auxiliares de pesquisa atuaram como secretárias, anotando os comentários e observações da atividade.

Os participantes da pesquisa foram divididos em subgrupos, selecionados de acordo com a ocupação deles, e as perguntas foram entregues impressas junto com papel e caneta para anotações. A reunião foi dividida em blocos. O primeiro bloco teve duração de 20 minutos para discussão entre os membros dos subgrupos das questões apresentadas; no segundo bloco, cada subgrupo tinha 10 minutos para expor seu ponto de vista de acordo com as questões abordadas; por fim, os últimos 15 minutos foram para discussão em conjunto de todos os participantes sobre as questões abordadas e outras ideias que surgiram. As questões chaves apresentadas para a discussão foram:

1. O que você entende por espaços de educação criativa no contexto do ensino da Administração?

2. Que elementos físicos (ex. móveis, ferramentas, decoração etc.) devem ter nos espaços de educação criativa no ensino de Administração?

3. Qual deve ser a forma dos espaços de educação criativa?

4. Como você indica que devem ser as paredes, se houver?

5. Quais cores você indica para serem usadas nos espaços de educação criativa?

6. Você considera que os espaços de educação criativa no curso de Administração devem conter elementos de lazer? Quais?

7. Você considera que os espaços de educação criativa devem usar algum tipo de sonorização? 
Os resultados foram qualitativamente categorizados e analisados segundo o critério do elemento físico central da pergunta norteadora da seção de Focus Group. Assim, a definição de espaço criativo de educação no âmbito do ensino universitário da administração foi associado à questão 1; a questão 2 reflete estruturas físicas; questão 3 se refere à forma; a questão 4 detalha, especificamente, a forma do elemento 'paredes'; e a questão 5 se dedica a cores usadas no espaço criativo de educação; a questão 6 verifica elementos de ócio; e, finalmente, a questão 7 trata do elemento sonorização. 


\section{RESULTADOS E ANÁLISES}

Para a realização desse Focus Group foram convidadas 12 pessoas, pois, apesar do número ideal indicado por Godoi (2015) ser 10 pessoas, colocou-se um percentual a mais devido a possíveis faltas de participantes. No final, 10 participantes se fizeram presentes. A distribuição do grupo pode ser apreciada no quadro 2 e manteve o equilíbrio buscado, por meio dos critérios anteriormente estabelecidos, para aumentar a confiabilidade dos resultados.

Quadro 2 Composição do Focus Group para cocriação de valor em espaços universitários de educação criativa

\begin{tabular}{|c|c|c|}
\hline GRUPO & PARTICIPANTES & CARACTERÍSTICA \\
\hline \multirow{4}{*}{$\begin{array}{c}\text { Grupo } 1 \\
\text { Professores }\end{array}$} & $\begin{array}{l}1 \text { professor de graduação e pós- } \\
\text {-graduação ( } 3 \text { anos de atuação) }\end{array}$ & $\begin{array}{l}\text { Área de Adminis- } \\
\text { tração geral e } \\
\text { Marketing }\end{array}$ \\
\hline & $\begin{array}{l}1 \text { professora de graduação (1 } \\
\text { anos de atuação) }\end{array}$ & Área de psicologia \\
\hline & $\begin{array}{l}1 \text { professora e coordenadora } \\
\text { administrativa de graduação ( } 8 \\
\text { anos de atuação) }\end{array}$ & $\begin{array}{l}\text { Área de } \\
\text { Contabilidade e } \\
\text { finanças }\end{array}$ \\
\hline & $\begin{array}{l}1 \text { professora de graduação e } \\
\text { pós-graduação ( } 2 \text { anos de atua- } \\
\text { ção) }\end{array}$ & $\begin{array}{l}\text { Área de empreen- } \\
\text { dedorismo e } \\
\text { administração geral }\end{array}$ \\
\hline \multirow{4}{*}{$\begin{array}{l}\text { Grupo } 2 \\
\text { Alunos }\end{array}$} & 1 aluna & Cursando $1^{\mathrm{a}}$ ano \\
\hline & 1 aluno/monitor & Cursando $2^{\mathrm{a}}$ ano \\
\hline & 1 aluno/ participante de PET & Cursando $3^{\mathrm{a}}$ ano \\
\hline & 1 aluno de $5^{\mathrm{a}}$ ano & Formando \\
\hline $\begin{array}{c}\text { Grupo } 3 \\
\text { Aluno de pós- }\end{array}$ & $\begin{array}{l}1 \text { servidor público concursado } \\
(5 \text { anos de atuação) }\end{array}$ & $\begin{array}{l}\text { Secretario do Curso } \\
\text { de Administração }\end{array}$ \\
\hline $\begin{array}{l}\text {-Graduação e } \\
\text { funcionários }\end{array}$ & $\begin{array}{l}1 \text { aluno do Programa de Pós- } \\
\text {-Graduação em Adm. }\end{array}$ & $\begin{array}{l}\text { Mestranda em admi- } \\
\text { nistração }\end{array}$ \\
\hline
\end{tabular}

Fonte: Trabalho de campo (2018). 
As principais áreas do ensino da Administração se encontram contempladas pela visão dos professores participantes, pois, atuando na administração geral, incluem-se visões de aulas teóricas de conhecimento amplo, bem como empreendedorismo. O ensino do Marketing que tem peculiaridades, assim como as áreas de Contabilidade e finanças, também foram consultadas. E o quadro se complementa com a visão da Psicologia, a qual neste Focus group tem dupla função, proporciona a visão a partir do ensino da Psicologia Organizacional e do profissional da Psicologia sobre os espaços que influenciam na criatividade e interação.

Com relação ao grupo de alunos, proporcionou-se a visão de alunos em todas as fases do curso, bem como alunos de pós-graduação, o qual também atua como docente-estagiário e pesquisador em formação. Por último, um colaborador da secretaria do curso estava presente, sendo um elemento de ponte entre professores-alunos e a UFCG.

A seguir, apresenta-se o resumo da transcrição dos resultados para cada grupo e por questão apresentada no Focus Group, seguindo os critérios de codificação e análise descritos na seção de metodologia. O quadro 3 resume os itens extraídos das falas do Grupo 1 (professores) no Focus Group sobre espaços de educação criativa para o ensino de Administração.

Observa-se, a partir das respostas, que o grupo de professores focou flexibilidade e interação exatamente como defende Romero (2013) e Alonso Monreal (2000). Também buscam as chamadas estruturas socializantes de Amabile (1996) e colaborativas de Silva, Silva e Coelho (2016). 
Quadro 3 Respostas do Grupo 1 - professores de graduação e pós-graduação em Administração

\begin{tabular}{|c|c|}
\hline $\begin{array}{l}\text { Espaço de } \\
\text { educação } \\
\text { criativa }\end{array}$ & $\begin{array}{l}\text { "Espaços que possuam configurações diferenciadas da } \\
\text { tradicional em termo de estrutura e que possibilitem a in- } \\
\text { teração entre professores e alunos, com uma nova abor- } \\
\text { dagem associando o uso de tecnologias para o acesso a } \\
\text { metodologias ativas de ensino", gamificação e métodos } \\
\text { diferenciados e associados ao ensino da administração. }\end{array}$ \\
\hline $\begin{array}{l}\text { Estruturas } \\
\text { físicas }\end{array}$ & $\begin{array}{l}\text { O grupo apresentou duas vertentes, uma no modelo de } \\
\text { coworking e outra vertente que acham que devem ter me- } \\
\text { sas moduláveis com rodízios para promover a interação } \\
\text { ou também utilizar mesas grandes, coletivas. As cadeiras } \\
\text { do tipo comuns. Também foi indicado mesas com vidros } \\
\text { para serem usadas como lousa. } \\
\text { Foi abordada a questão de pontos de conexões de entrada } \\
\text { de energia elétrica para que todos possam usar seus equi- } \\
\text { pamentos (computadores e afins), boas conexões de rede } \\
\text { e disponibilidade de softwares para atividades práticas } \\
\text { que sejam associados ao ensino e desenvolvimento da ad- } \\
\text { ministração; softwares para atividades práticas associadas } \\
\text { ao conteúdo para que aja uma maior interação; uso de } \\
\text { smartphones de forma otimizada dentro da sala de aula. }\end{array}$ \\
\hline Forma & $\begin{array}{l}\text { Concordaram que deve ter paredes, ambientes fechados, } \\
\text { mas com uso de elementos de vidro, como divisórias, ja- } \\
\text { nelas para que melhore o visual e interação, mesas com } \\
\text { tampo de vidro que possam ser usadas para escrever tam- } \\
\text { bém. }\end{array}$ \\
\hline
\end{tabular}


Paredes

Paredes de vidro devem ser usadas como ferramenta, além de ser o isolamento, ela possa ser utilizada para escrever nela, foi uma das sugestões que permite usá-las como louças e outras atividades didático-pedagógicas. Também o uso de paredes pintadas com tinta especial que as torna passíveis de usar como louças, como base para serem colocadas notas adesivas com fácil remoção para uso posterior. Paredes com grafite que estimulem a criatividade dos alunos e professores e sejam emblemáticos para o público envolvido também foi recomendado. Todos optaram por um estudo direcionado à psicologia das cores, para um bom e eficaz resultado em relação a questão. No entanto, alguns professores destacaram que

Cores o uso de algumas cores fortes que possam estimular os alunos, retendo a atenção do aluno, pode ajudar na captação da atenção do estudante e na memorização, estimulando os alunos, mas sempre com cuidado, pois o exagero pode 'cansar' as pessoas na sala.

Os professores responderam que devem conter elementos de lazer, pois possibilitam maior interação entre os alunos e permitem o uso de didáticas relacionadas a gamificação que tem sido associada a administração; jogos

Elementos que estimulem a memória, jogos de estratégia, a criatide ócio vidade e o pensamento lógico, atividades lúdicas (baú com fantoches, com fantasias, com coisas que possam ser usadas para o estímulo da criatividade, por exemplo), um espaço com um cafezinho e com sofá, uma área aconchegante no estilo de um ambiente profissional.

Consideraram necessário um espaço com uma boa sono-

Sonori- rização e acústica que favoreça o uso da criatividade, com

zação equipamentos que permitam, quando necessário, o uso de som, de aulas multimídias e de teleconferências.

Fonte: Trabalho de campo (2018). 
As mesmas questões foram discutidas pelos alunos na fase 1 do Focus Group e obtiveram as respostas que se apresenta no quadro 4.

O grupo de alunos se preocupou mais com a flexibilidade e a atualização dos ambientes do que com a interação. Destacam a importância do uso de tecnologias, computadores, softwares e claramente associam o conceito de espaço criativo de educação às TICs (Tecnologias de Informação e Comunicação). Igualmente ao grupo de professores, consideram que os espaços de aula devem ser fechados, mas registram a preocupação de 'não se sentirem em uma caixa', por isso o uso de paredes de vidro e amplas janelas. Fato que indica que a opressão do ambiente fechado é considerada desestimulador da criatividade. O ócio é indicado como 'ócio criativo e educador', pois salientam o uso de jogos de estratégia para melhorar a capacidade de tomada de decisão. No geral, os estudantes visualizam um ambiente empresarial moderno e interativo que proporcione metodologias ativas de educação. As cores são suaves, mas com elementos de destaque, e o uso da música é recomendado com moderação.

A visão dos estudantes também está alinhada à literatura da área, pois eles intuitivamente buscam elementos ricos de estímulos, como defende Torre (2006), mas ao mesmo tempo um ambiente com sensação de segurança e tranquilidade (SILVA; SANTOS, 2015). O uso de tecnologias se mostra para os estudantes com uma relação direta entre a criatividade e um espaço de educação adequado, sendo também um elemento destacado nos estudos de Padula (2016) e Iftakhar (2016). 
Quadro 4 Respostas do Grupo 2 - Estudantes de Graduação em Administração

\begin{tabular}{|c|c|}
\hline $\begin{array}{l}\text { Espaço de } \\
\text { educação cria- } \\
\text { tiva }\end{array}$ & $\begin{array}{l}\text { O espaço deve ter flexibilidade, propício para o ensino da } \\
\text { teoria e da prática com materiais adequados, proporcio- } \\
\text { nando a aplicação de tecnologias ao curso que possa ser } \\
\text { adequada a cada disciplina. }\end{array}$ \\
\hline $\begin{array}{l}\text { Estruturas } \\
\text { físicas }\end{array}$ & $\begin{array}{l}\text { Para constituir um espaço físico, é necessário resgatar o } \\
\text { ambiente profissional para dentro do espaço acadêmico, } \\
\text { sua estrutura seria com mesas em formato de reunião, } \\
\text { quadros interativos, ferramentas necessárias como com- } \\
\text { putadores com software adequado a aplicação e análises } \\
\text { administrativas de cada área de estudo do curso. }\end{array}$ \\
\hline Forma & $\begin{array}{l}\text { acilidade para visibili- } \\
\text { s. }\end{array}$ \\
\hline Paredes & $\begin{array}{l}\text { Predominância de vidros, divisórias de vidros e sempre } \\
\text { com a preocupação da visualização do todo. }\end{array}$ \\
\hline & Predominância de cores claras com detalhes vivos. \\
\hline $\begin{array}{c}\text { Elementos de } \\
\text { ócio }\end{array}$ & $\begin{array}{l}\text { Devem conter sim e devem ser compostos por jogos que } \\
\text { estimulem a capacidade de decisão, estratégia e que esti- } \\
\text { mulem o raciocínio lógico, jogos de xadrez, poker, pois } \\
\text { ao mesmo tempo que se divertem os alunos passam a } \\
\text { ser mais estrategistas e ter um maior poder de tomada } \\
\text { de decisão. }\end{array}$ \\
\hline Sonorização & $\begin{array}{l}\text { Sim, mas só em momentos específicos, de modo que } \\
\text { não atrapalhe o raciocínio, visto que nem todos se con- } \\
\text { centram com música. Então, deve se ter um consenso } \\
\text { em relação a essa temática. }\end{array}$ \\
\hline
\end{tabular}

Fonte: Trabalho de campo (2018).

O terceiro grupo foi composto por um funcionário da secretaria do curso de Administração e uma aluna da pós-graduação em Administração, tendo obtido as respostas que se apresentam no quadro 5 . 
Quadro 5 Respostas do Grupo 3 -Estudantes de Pós-Graduação e servidores

\begin{tabular}{|cl|}
\hline $\begin{array}{c}\text { Espaço de } \\
\text { educação } \\
\text { criativa }\end{array}$ & $\begin{array}{l}\text { Deve ser um espaço de educação que possa estimular a cria- } \\
\text { tividade e a comunicação entre os envolvidos no processo de } \\
\text { aquade de utilizar o modelo de sala Google, que } \\
\text { emédio e fundamental, indicaram também um es- } \\
\text { paço direcionado para notas autoadesivas, que não tenham } \\
\text { barreiras físicas que possibilitem a criatividade e interação e } \\
\text { trabalho em grupo. }\end{array}$ \\
$\begin{array}{l}\text { Os elementos que podem ser adotados são lousas digitais, } \\
\text { paredes e mesas de vidro ou lousa, mesas coletivas que pos- } \\
\text { sibilitem a interação entre os participantes, internet, com- }\end{array}$ \\
Estruturas & $\begin{array}{l}\text { putadores, notas adesivas, plataformas digitais, para com- } \\
\text { partilhar informações e acompanhar o desenvolvimento } \\
\text { de atividades entre os diferentes atores do processo e que a } \\
\text { informação permita a participação e desenvolvimento das }\end{array}$ \\
ideias entre o grupo.
\end{tabular}

Fonte: Trabalho de campo (2018). 
Esse último grupo associa o conceito de espaço criativo de educação com comunicação, interação e com o chamado modelo de sala Google já adotado em algumas escolas secundárias no Brasil. Esse tema estudado por Iftahar (2016), por Bottentuit Junior, Lisbôa, Coutinho (2011), entre outros. É preciso salientar que uma das funcionalidades do espaço Google de educação são as ferramentas tecnológicas que proporcionam a metodologia de Flipped Classroom (aula invertida), método muito usado em faculdades e colégios norte-americanos de ponta, pelo qual se muda a lógica de organização da classe (O)FLAHERTY; PHILLIPS, 2015). Por esse formato os alunos pesquisam e aprendem o conteúdo em casa e usam o momento de aula para projetos conjuntos e uso de recursos interativos. A visão da funcionalidade de mesas e paredes como louças é mantida também neste grupo; e, igualmente aos professores, indicam que as cores devem passar por um estudo de especialista da área. Como elementos de ócio, diferentemente dos outros grupos que focaram em ser aconchegante, mas com aparência 'empresarial', o grupo 3 incluiu elementos culturais locais, com o uso de redes para descanso. A música também foi indicada com moderação, seguindo a tendência de ambientes que gerem conforto e tranquilidade como indica Silva e Santos (2015).

Após essa primeira fase, os três grupos discutiram suas respostas e definiram novos elementos de criação de valor para os espaços criativos de educação no âmbito do ensino universitário de Administração, a saber:

$\checkmark$ elementos de lazer sugeridos: revistas da área, sofás para descanso, cantinho do cafezinho;

$\checkmark$ cores comentadas: cores fortes que consigam estimular a criatividade e prender a atenção dos alunos;

$\checkmark$ estruturas físicas: mesas moduláveis e smart TV;

$\checkmark$ ferramentas sugeridas: uso de smartphones, salas com internet, salas com dispositivos para uso de equipamentos eletrônicos dos alunos, softwares relacionados ao estudo e ensino da Administração. 
Uma interpretação geral das respostas obtidas com os três grupos conduz a pensar uma sala de aula como um espaço de educação criativa para o curso de Administração, como sendo um ambiente físico totalmente diferente do usado hoje em dia. A cocriação de valor criada pelo grupo para o modelo de sala de aula remete a uma mescla entre areas de coworking e espaços empresariais, sendo que o grupo concorda que as atuais salas tradicionais não proporcionam a inovação e o pensamento criativo para o aprendizado da Administração, mesmo nas áreas de caráter mais tecnicista como a Contabilidade e financeira. Aportes teórico-empíricos de Matias et al (2015) e de Grillo et al (2014), também focadas na cocriação de valor com alunos universitários, mostraram resultados em sentido similar aos da presente pesquisa, concluindo que o contexto da sala de aula impacta sobre o comportamento de colaboração, além de afetar os relacionamentos e a criatividade.

O resultado acumulado da cocriação de valor realizada no presente estudo reuniu os discursos dos três coletivos presentes no Focus Group como sendo: interação, paredes louças, mobilidade, mesas coletivas, jogos, tecnologias, espaço de coworking, internet e estrutura física não tradicional. Esses elementos têm semelhanças com outros estudos como, por exemplo, em Silva e Santos (2015) no ambiente de aprendizagem projetado no Observatório de Pesquisa e Prática em Administração (OPPA), da Universidade Federal da Paraíba, cujo foco foi em sala de aula que permitam a trocar experiências, o diálogo, com conforto, sensação de segurança, tranquilidade e vivências gerando criatividade.

A partir da sobreposição de ideias, o conceito de espaço criativo de educação no ensino da Administração pode ser definido como: espaços que possuam configuração estrutural diferenciada da tradicional para proporcionar interação e comunicação, possibilitando o uso de novas abordagens; sejam flexíveis e utilizem a tecnologia para o acesso a metodologias ativas de ensino; gamificação e métodos diferenciados no ensino da Administração, aliando a teoria e a prática; e, assim, sendo ambientes de criatividade e inovação. Enquanto os elementos deste espaço estão sintetizados na Figura 2. 
No geral, os elementos indicados pelos coletivos (figura 2) proporcionam o que Silva, Silva e Coelho (2016) defendem um conhecimento propagado de forma construtiva e cujas estruturas físicas sejam mais dinâmicas, interativas e colaborativas para o aprendizado. Na mesma direção, Fiorin e Silva (2018) estudaram a estética das salas de aula e os sentimentos produzidos nos discentes e docentes, concluindo que o ideal de sala de aula na atualidade é baseado em flexibilidade, horizontalidade e espaços com mobilidade de arranjos.

Figura 2 Elementos estruturais associados às palavras que foram destaque nos discursos dos três coletivos presentes no Focus Group de espaços criativos de educação

\section{CONCEITO DE ESPAÇO CRIATIVO DE EDUCAÇÃO PARA O ENSINO DE} ADMINISTRAÇÃO

"Espaços que possuam configuração estrutural diferenciada da tradicional para proporcionar interação e comunicação, possibilitando o uso de novas abordagens, sejam flexíveis e utilizem a tecnologia para o acesso a metodologias ativas de ensino, gamificação e métodos diferenciados no ensino da administração, aliando a teoria e a prática, e assim, sendo ambientes de criatividade e inovação."

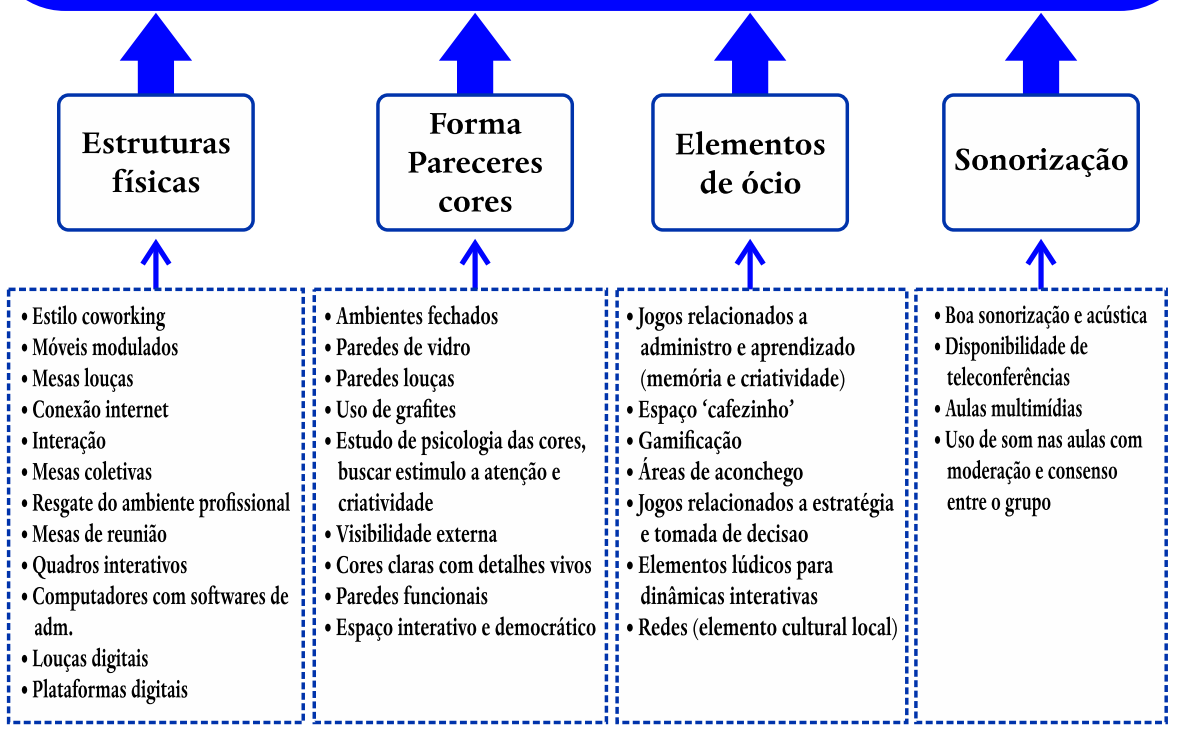

Fonte: Elaborado pelos autores. 
Pode-se observar que, apesar da técnica de Focus Group não primar pelo consenso entre os grupos, mas sim pela diversidade de ideias, houve um reconhecido grau de consenso na forma como cada coletivo imagina um espaço de educação criativo em termos de sua forma e funcionalidade. Destaca-se que o valor criado pelo grupo segue o que é defendido pelos autores tanto da inovação educativa como dos estudiosos da educação criativa. Basicamente, o valor criado neste grupo atende o que é indicado na literatura, pois Romero (2013) evidencia a flexibilidade e a interação nos ambientes, na mesma linha de estímulos. Silva, Silva e Coelho (2016), Fiorin e Silva (2018) e Alonso Monreal (2000) salientam o equilíbrio entre liberdade e estrutura, a oportunidade entre escolhas e descobertas e a aquisição de conhecimentos específicos dos domínios. Por sua vez, Amabile (1996) sempre destacou a sociabilização por meio dos ambientes; Torre (2003), a riqueza de estímulos; Silva, Silva e Coelho (2016) e Fiorin e Silva (2018) destacam a flexibilidade dos ambientes e Souza (2015), a sensação de segurança e tranquilidade.

O que se extrai do padrão imaginado pelos grupos tem uma semelhança com os modelos de coworking, sendo uma forma organizacional adotada largamente ao redor do mundo, cuja filosofia é integrar e proporcionar ambientes de inovação e criatividade, proporcionando o crescimento conjunto de todos os envolvidos. 


\section{CONSIDERAÇÕES FINAIS}

É fundamental a abordagem de repensar os espaços dentro da universidade, pois com todos os avanços tecnológicos, cada vez se torna mais necessária a inovação dentro e fora das salas de aula. O novo cenário educacional indica a necessidade de mudanças que venham a ser estimulantes para todos os coletivos envolvidos no processo de aprendizagem. De acordo com Libedinsky $(2001,2011)$, a inovação educativa pode ser classificada em institucional, curricular e didática. No presente caso, da proposta de um espaço de educação criativa para o ensino de Administração, cocriado a partir dos diferentes coletivos (atores) do ambiente acadêmico universitário, gera uma inovação educativa institucional que proporciona a inovação educativa didática.

A função da universidade é preparar as pessoas para o mercado cada vez mais exigente e verificar as possíveis falhas existentes no processo de educação clássico, inovando no processo de educação, visando o mundo atual. É fato que a forma de educar está mudando e os espaços de salas de aula também. Essas mudanças, atualmente, são mais observadas no ensino fundamental e médio, nos quais adotam certos tipos de metodologias que visam estimular a criatividade dos alunos, enquanto a universidade tem se mantido na versão clássica, em sua maioria.

Este trabalho mesclou a aplicação de métodos de cocriação de valor proposta por Prahalad e Ramaswamy (2004) e reatualizada pela perspectiva de Ramaswamy e Ozcan (2018) com o método de Focus Group e o valor cocriado indicou que uma sala de aula como espaço criativo de educação deve ter semelhança com a forma organizacional das empresas modernas e dos espaços baseados em filosofia de coworking. Diante dos resultados se pode depreender que a universidade, no seu modelo tradicional de estrutura de espaços de educação, ficou para trás nesta tendência de mercado, correndo o risco de perder sua funcionalidade enquanto preparadora de profissionais para um mercado, cuja base competitiva está no pensamento criativo e na inovação. Além disso, o experimento realizado comprova que a técnica de Focus Group se adapta à formalização de processos de cocriação 
de valor presencial e pode ser usada para aplicar os passos indicados por Prahalad e Ramaswamy (2004).

Os espaços de educação criativa, como idealizado pelo grupo, podem estimular a criatividade dos alunos e de todos os atores envolvidos, provocando mudanças que acrescentem muito na formação acadêmica e profissional tanto do aluno como dos demais coletivos, preparando-o para o mercado de trabalho atual. Diante da problemática dos espaços clássicos versus criativos de educação, o método de focus group permitiu analisar e elencar alguns fatores que possam contribuir para a criação de espaço criativo de educação, a partir de três coletivos diferentes.

Ainda que seguindo um rigor do método de Focus Group e cocriação de valor, bem como um protocolo de pesquisa, não se pode generalizar os resultados alcançados, pois foi investigada uma única instituição de ensino superior e realizado um Focus Group. No entanto, interessantes achados foram obtidos. O resultado identificou elementos que foram citados por todos que participaram da pesquisa como importantes para a criação desses espaços, pois apesar do focus group não buscar consenso, no geral, a maioria dos pontos discutidos teve posicionamentos bem parecidos e seguiu a tendência observada na revisão de literatura. Liburd e Hjalager (2010) afirmam que a educação precisa sair desse modelo tradicional e alcançar um modelo de inovação, atendendo a necessidade do mercado, indo além das paredes da universidade e, desse modo, estimulando a criatividade de todos os envolvidos no processo de cocriação de valor dentro e fora da universidade. No mesmo sentido, Fini (2018) afirma que adotar metodologias inovadoras de aprendizagem e suas relações com o mundo do trabalho é uma imposição atual, para que as Instituições de Ensino Superior (IES) não percam seu papel fundamental na formação de cidadãos preparados para atuarem na sociedade em que vivem.

O grupo de participantes mostrou consenso quanto ao desejo de produzir aulas mais interativas e ativas, assim como o quanto consideram desestimulante a sala de aula clássica, tendo salientado que, inclusive, pode estar atuando sobre a evasão escolar, pois os jovens atualmente buscam por ambientes mais estimulantes. O conceito de espaço criativo de educa- 
ção ficou associado à sua flexibilidade, capacidade de proporcionar interação interna e externa, uso de tecnologias e de elementos funcionais e estruturas, do mesmo modo que mobílias de uso coletivo e não individualista. A funcionalidade das paredes e mesas como lousas é um destaque para todos os grupos.

Assim, considerando esses resultados encontrados para a UFCG, a maioria das salas de aula está com um modelo ultrapassado de ensino, o que pode estar gerando um bloqueio do desenvolvimento da criatividade de todos os envolvidos, alunos e professores. E, apesar de não ser o objetivo deste trabalho, pode-se observar que os elementos indicados para os espaços criativos de educação não possuem um custo muito acima do que já é praticado hoje nos espaços tradicionais. O que muda são os formatos de estruturas individualistas para coletivas, de ambientes insípidos e sem personalidade para ambientes aconchegantes, estimulantes e personalizáveis.

Enfim, pode-se considerar que o resultado do Focus Group na UFCG criou um modelo de espaço criativo de educação bem parecido com o modelo de espaços de coworking, o que mostra uma total contradição com o atual espaço utilizado, de mesas individuais, espaços fechados sem elementos decorativos ou de ócio, nem áreas funcionais. Segundo os resultados deste trabalho, se a universidade deseja manter seu papel de líder na educação empreendedora, inovadora e preparatória para o mercado necessita, urgentemente, reavaliar suas estruturas fisicas e adaptá-las, trazendo a visão empresarial e da sociedade para dentro do modelo universitário, não somente no seu discurso ou prática, mas na sua estrutura mais básica: a sala de aula. Para extrapolar estes achados para níveis mais gerais, recomendase como estudos futuros a realização de pesquisas adicionais em outras IES e a comparação em ambiente de graduação e pós-graduação, cursos presenciais e Educação a Distância (EAD), assim como um benchmarking com outras IES de referência dentro do contexto estudado. 


\section{REFERÊNCIAS}

ALONSO MONREAL, C. Qué es la creatividad. Madrid: Biblioteca Nueva. 2000.

AMABILE, T. A. Creativity in context. Boulder, CO: Westview Press. 1996.

ARCHER, W.; GARRISON, R.; ANDERSON, T. Adopting disruptive technologies in traditional universities: Continuing education as an incubator for innovation. Canadian Journal of University Continuing Education, v. 25, n. 1, p. 13-44, 2013. DOI: 10.21225/D5Z015

BACICH, L.; MORAN, J. Metodologias ativas para uma educação inovadora: uma abordagem teórico-prática. Penso Editora, 2017.

BATISTA-CANINO, R. M.; BOLÍVAR-CRUZ, A.; MEDINA-BRITO, P. Monitorización del proceso emprendedor a través del modelo de negócio. Innovar, v. 26, n. 61, p. 83-102, 2016.

BECKER, S. A.; Et al. NMC horizon report: 2017 higher education edition. The New Media Consortium, 2017.

BERNAL VÁZQUEZ, J. La Creatividad en la clase de Música.: "hacer y expresar música en la escuela", en Comprender y Evaluar la Creatividad. Un recurso para mejorar la calidad de la enseñanza. Aljibe. Málaga, v. 1, p. 415 - 425, 2006.

BLACK, I.; VELOUTSOU, C. Working consumers: Co-creation of brand identity, consumer identity and brand community identity. Journal of Business Research, v. 70, p. 416429, 2017.

BOTTENTUIT JUNIOR, J. B.; LISBÔA, E. S.; COUTINHO, C. P. Google educacional: utilizando ferramentas web $2.0 \mathrm{em}$ sala de aula. EducaOnline, v. 5, n.1, p. 17-44, 2011.

BORYS, B.; JEMINSON, D. B. Hybrid arrangements as strategic alliances: theoretical issues in organizational combinations. Academy of Management Review, v. 14, n.2, p. 23449, 1989.

BRAMBILLA, F. R.; DAMACENA, C. Cocriação de valor no ensino superior privado: uma análise etnometodológica com alunos de administração de uma universidade do sul do Brasil. Administração: Ensino e Pesquisa, v. 13, n. 3, p. 455-490, (jul./ago./ set). 2012.

BRUBACHER, J. Higher education in transition: History of American colleges and universities. Routledge, 2017.

CATHCART, H.; ESLAND, G. The compliant-creative worker: the ideological reconstruction of the school leaver. In: Education and social change. Routledge, 2017. p. 173-192, 2017.

CHIM-MIKI, A. F.; GÂNDARA, J. M.; BATISTA-CANINO, R. M. Collaborative network organizations as platform for value co-creation in tourism destinations: an analysis of Foz do Iguaçu, Brazil. International Journal of Tourism Policy, v. 7, n. 1, p. 42-57, 2017.

ELISONDO, R. C.; DONOLO, D. S.; RINAUDO, M. C. Ocasiones para la creatividad en contextos de educación superior. Revista de Docência Universitária, n. 4, p. 1-16, 2009. 
FINI, M. I. Inovações no ensino superior metodologias inovadoras de aprendizagem e suas relações com o mundo do trabalho: desafios para a transformação de uma cultura. Administração: Ensino e Pesquisa, v. 19, n. 1, p. 176-183, (jan-abr). 2018. DOI:10.13058/ raep.2018.v19n1.982

FIORIN, M.M.B; SILVA, S.F.P. Percepções Julgamentos Estéticos da Sala de Aula. In: ENANPAD, 42., 2018, Curitiba, PR. Anais ...Curitiba: ANPAD, 2018.

GODOI, C.K.; COELHO, A.L.D.A.L.; SERRANO, A. Elementos epistemológicos e metodológicos da Análise Sociológica do Discurso: Abrindo possibilidades para os estudos organizacionais. Organizações \& Sociedade, v. 21, n. 70, p. 509-535, (Jul./Set). 2015.

GRÖNROOS, C. Service logic revisited: who creates value? And who co-creates? European business review, v. 20, n. 4, p. 298-314, 2008.

GRILLO, T. L. H. et al. Cocriação de valor com alunos: uma análise da influência social e do engajamento na disciplina como antecedentes de feedback do estudante. Administração: Ensino e Pesquisa, v. 15, n. 3, p. 533-559, 2014.

GUTIÉRREZ, J. Grupo de Discusión:¿ Prolongación, variación o ruptura con el focus group? Cinta de moebio, n. 41, p. 105-122, 2011.

IFTAKHAR, S. Google classroom: what works and how? Journal of Education and Social Sciences, v. 3, p. 12-18, 2016.

LIBEDINSKY, M. La innovación en la enseñanza. Diseño y documentación de experiencias de aula. Buenos Aires: Paidós. 2011

LIBURD, J.; HJALAGER, A. M. Changing approaches towards open education, innovation and research in tourism. Journal of Hospitality and Tourism Management, v. 17, p. 12-20, 2010.

LOI, D.; DILLON, P. Adaptive educational environments as creative spaces. Cambridge Journal of Education, v. 36, n. 3, p. 363-381. 2006.

LOGAN, L. M.; LOGAN, V. G. Estrategias para una enseñanza creativa. Barcelona: Oikos-tau, 1980.

MERTON, R. K.; FISKE, M.; KENDALL, P. L. The focused interview: A manual of problems and procedures (2nd ed.). New York: Free Press. 1990.

MCKENNEY, S.; REEVES, T.C. Conducting educational design research. Routledge, 2018.

MATIAS, A. P. et al. Cocriação de Valor no Ensino Superior Privado: Um estudo de caso no curso de administração da Faculdade Capivari. In: COLÓQUIO INTERNACIONAL DE GESTÃO UNIVERSITÁRIA, 15., 2015, Mar del Plata, Buenos Aires. Anais... Disponível em: https: / / repositorio.ufsc.br/handle/123456789/136125. Acesso em: 04 out.2018.

MEDINA-MUÑOZ, D.R.; MEDINA-MUÑOZ, R.D.; ZÚÑIGA-COLLAZOS, A. Tourism and innovation in China and Spain: a review of innovation research on tourism. Tourism Economics, v. 19, n. 2, p. 319-337, 2013. 
O)FLAHERTY, J.; PHILLIPS, C. The use of flipped classrooms in higher education: A scoping review. The internet and higher education, v. 25, p. 85-95, 2015.

PAYNE, A.F.; STORBACKA, K.; FROW, P. Managing the co-creation of value. Journal of the academy of marketing science, v. 36, n. 1, p. 83-96, 2008.

PADULA, R.S. Inovação na Educação: ganhos no interesse e conhecimento com uso da tecnologia da informação IN: XL ENCONTRO DA ANPAD, 2016, Costa do Sauipe BA. Anais... Costa do Sauipe: ANPAD, 2016.

PRAHALAD, C. K.; RAMASWAMY, V. Co-opting customer competence. Harvard business review, v.78, n.1, p. 79-90, 2000.

PRAHALAD, C. K.; RAMASWAMY, V. Co-creating unique value with customers. Strategy \& leadership, v. 32, n. 3, p. 4-9, 2004.

RAMASWAMY, V.; GOUILLART, F. Building the co-creative enterprise. Harvard business review, v. 88, n. 10, p. 100-109, 2010.

RAMASWAMY, V.; GOUILLART, F. It)s about human experiences... and beyond, to co-creation. Industrial Marketing Management, v. 2, n. 40, p. 195-196, 2011.

RAMASWAMY, V.; GOUILLART, F.; OZCAN, K. What is co-creation? An interactional creation framework and its implications for value creation. Journal of Business Research, $\mathrm{v}$. 84, p. 196-205, 2018.

RAMIREZ, R. Value co-production: intellectual origins and implications for practice and research. Strategic Management Journal, n. 20, 49-51, 1999.

ROMERO, S.C. Creativity in education, its development from a pedagogical perspective. Journal of Sport and Health Research, v. 5, n. 2, p. 221-228, 2013.

SAARIJÄRVI, H; KANNAN, P.K.; KUUSELA, H. Value co-creation: theoretical approaches and practical implications. European Business Review, v. 25, n. 1, p. 6-19, 2013.

SELTZER, E.; MAHMOUDI, D. Citizen participation, open innovation, and crowdsourcing: Challenges and opportunities for planning. Journal of Planning Literature, v. 28, n. 1, p. 3-18, 2013.

SILVA, M.D.S.; SILVA, A.B.; COELHO, A.L.A.L. Implicações do Ambiente de Aprendizagem na Formação de Mestres Profissionais em Administração. In: XL ENANPAD, 40., 2016, Costa do Sauipe, BA. Anais...Costa do Sauipe: ANPAD, 2016.

SILVA, M. D. S.; SANTOS, G. T. Relato das Experiências Vivenciadas no Ambiente de Aprendizagem Projetado no Observatório de Pesquisa e Prática em Administração-OPPA. In: ENCONTRO DE ENSINO E PESQUISA EM ADMINISTRAÇÃO E CONTABILIDADE, 5., 2015, Salvador, BA. Anais... Salvador: EnEPQ, 2015.

SILVA, A. B. D. et al. Problem-based learning: A proposal for structuring PBL and its implications for learning among students in an undergraduate management degree program. Revista de Gestão, v. 25, n. 2, p. 160-177, 2018. 
ADRIANA FUMI CHIM-MIKI, DANIELI BARBOSA CAMPOS \& LUCIA ISSN 2358-09I7 SILVA ALBUQUERQUE DE MELO

TORRE, S.D.L. Comprender y evaluar la creatividad. Volumen 2. Málaga: Ediciones Aljibe. 2006.

VARGO, S. L.; LUSCH, R. F. Evolving to a New Dominant Logic for Marketing. Journal of Marketing, v. 68, n. 1, p. 1-17, 2004.

VARGO, S. L.; LUSCH, R. F. It's all b2b... and Beyond: Toward a Systems Perspective of the Market. Industrial Marketing Management, v. 40, n. 2, p. 181-187, 2011. 


\section{DADOS DOS AUTORES}

\section{ADRIANA FUMI CHIM-MIKI adriana.chimmiki@gmail.com}

Doutora em Turismo, Economia e Gestão pela Universidad de Las Palmas de Gran

Canaria, Espanha

Instituição de vinculação: Universidade Federal de Campina Grande

Campina Grande/PB - Brasil

Áreas de interesse em pesquisa: Coopetição; Competitividade; Empreendedorismo; Redes interorganizacionais; Gestão social; Turismo; Ensino.

Rua Tomas Soares de Souza, 315, ap. 305 Catolé Campina Grande/PB 58410-235

\section{DANIELI BARBOSA CAMPOS danielibcampos@gmail.com}

Bacharel em Administração pela UFCG

Instituição de vinculação: Universidade Federal de Campina Grande

Campina Grande/PB - Brasil

Áreas de interesse em pesquisa: Competitividade; Empreendedorismo; Educação; Inovação.

\section{LUCIA SILVA ALBUQUERQUE DE MELO luciasalbuquerque@gmail.com}

Mestre em Contabilidade pela UnB

Instituição de vinculação: Universidade Federal de Campina Grande

Campina Grande/PB - Brasil

Áreas de interesse em pesquisa: Contabilidade Societária; Gestão Social; Ensino e Pesquisa em Contabilidade e Administração. 